\title{
Social Cognitive Smart Robots: Guide, Seller, Lecturer, Vacuum Cleaner, Nurse, Volunteer, Security Guard, Administrator
}

\author{
Evgeniy Bryndin \\ Research Center "Estestvoinformatika", Scientific Department, Novosibirsk, Russia
}

Email address:

bryndin15@yandex.ru

To cite this article:

Evgeniy Bryndin. Social Cognitive Smart Robots: Guide, Seller, Lecturer, Vacuum Cleaner, Nurse, Volunteer, Security Guard, Administrator. Communications. Vol. 7, No. 1, 2019, pp. 6-12. doi: 10.11648/j.com.20190701.12

Received: February 1, 2019; Accepted: March 11, 2019; Published: March 25, 2019

\begin{abstract}
There are two main approaches to implementation of the software of hardware of technological thinking of cognitive robots. The first approach - machine learning. Such cognitive robots are used in services industry for commercial purposes. Cognitive robots on the basis of modeling of communicative and associative logic of imitative reflection of the person are used as lecturers and consultants when concepts and knowledge are strictly defined. The communicative and associative logic allows creating the robot capable to communicate with the help of the speech in various languages. Now in the world in many spheres of activity Russian, European, Japanese, Chinese, American smart robots are used. Development of technologies conducts to the fact that new robots appear. Create robots and train them for work in the social sphere. Robots can find environmental pollution, fire-dangerous situations and successfully prevent them. A few years ago there were also mobile robots able to be guided in space.
\end{abstract}

Keywords: Imitative Thinking and Behavior, Cognitive Systems, Social Smart Robots

\section{Introduction}

Imitative thinking represents communicative and associative processes with words, phrases, offers and judgments. At the computer level imitative thinking is imitated by communicative and associative processes with symbolical language elements of knowledge. Imitation of imitative thinking at the computer level is carried out on the basis of symbolical language communicative logic and network communicative and associative representation of symbolical language elements of knowledge.

The information circle of the person represents the connected signs of environment of the first alarm level and the language intrinsic environment of the second alarm level. At the first alarm level information on a surrounding reality in the form of signs, signs of situational schemes and situational schemes is stored. At the second alarm level symbolical elements of knowledge are stored in the intrinsic environment: words, phrases, offers, and judgments.

The hardware-software information environment of the computer stores symbolical elements of knowledge in coded form with an intrinsic marking supplied with all signs of representatives of a reality and connected signs of situational schemes. To an element of knowledge from the hardwaresoftware environment of the computer there corresponds the element of knowledge from the intrinsic circle of the person connected with the same signs and the scheme of the first alarm level. These elements of knowledge correspond to the same fragments of a reality. As the hardware-software environment works with sign elements of knowledge as language, it is necessary to supply still elements of knowledge of the hardware-software environment with syntactic structures and a language marking according to grammar and rules of a written language to use language practice of the person for understanding of sense of written texts.

The hardware-software symbolical language environment which elements of knowledge have the marking described above and the semantic circle of the expert always correspond to the same surrounding reality or abstraction.

Therefore it is possible to imitate symbolical and language thinking of the person at the level of cogitative acts, keeping 
compliance between contents and language symbolical elements of knowledge, substituting surrounding or virtual (abstract) reality for the language symbolical description with functional the syntax, selecting acts of thought process, keeping the relations between elements of knowledge and representatives realities and developing experience of understanding and transfer of sense.

The person joins semantic acts through the existential, cause and effect relations. Symbolical structures of elements of knowledge are built in memory of the person according to communicative communications of the first alarm level between the corresponding signs of representatives of a reality or abstraction. Symbolical elements of knowledge can be displayed one-to-one in the coded patterns of electric activity of memory of the robot.

At such robot semantic acts of the person are substituted for semantic synthesis of the corresponding coded patterns, keeping univocity of structures and communication language communications with the corresponding elements of knowledge, it is possible to carry out imitation of symbolical language thinking by means of the robot. The symbolical and language communicative logic of the person is the cornerstone of imitation of symbolical language thinking.

Imitation of symbolical language thinking is carried out on communicative and associative communications of elements of knowledge. Therefore it is important to have communicative communications at a stage of representation of knowledge. For this purpose it is necessary to specify subject domain of knowledge, a situation for judgments, the situational moment for offers. Situations connect the situational moments in the semantic focused representation of knowledge of subject domain. Representation of knowledge is essential for imitation of symbolical thinking as elements of knowledge and communicative and associative communications between them directly participate in cogitative acts. Elements of knowledge: words, phrases, offers, judgments are stored in memory of the person with communication and associative communications between them, the displaying communications between the corresponding representatives of a reality or abstraction.

Symbolical language thinking offers and judgments represents communicative and associative process of realization of information needs of the person. Information requirement is formed in subject domain and is implemented in her system of knowledge.

The person gathers experience of realization of information requirements by means of imitative thinking on the basis of cogitative experience of others, accumulating information requirements and their realization in memory. Then, combining the initial information requirements which are in memory of person builds new information requirements. The person realizes new information requirement the corresponding combination of realization of initial information requirements, components new. At the person imitative thinking thus develops.

If to store realization of information needs for a type of the coded patterns of elements of knowledge in hardware- software memory, then it is possible to automate process of realization of information requirements on communicative and associative logic with use of a functional natural language [1-3].

To touch of the person there correspond four distinct feelings: cold, heat, pain and pressure. On the robot it is possible to assign a maintenance task in admissible limits of the parameters of heat and cold, vital for the person. The robot capability equivalent to perception of pain at the person, can warn about an overload. Perception of pressure is function without which the robot can't do. This function can be entered in the robot by various methods depending on purpose of the robot. It is especially important when fingers of the robot take various, sometimes fragile, objects.

Touch sensors at the person are very sensitive and numerous that allows use them for distinction of a form. It is very desirable to allocate with a similar capability the robot, but now this task is already not really difficult.

The main objective of reflex activities of the person is his viability. It is possible to allocate the robot with the similar capability providing its mobility. In certain cases it will be hard to be performed. The method of exact indication of position of the robot is implemented by the navigation equipment, based on comparison of provisional regulations of impulses with provisional regulations of reference impulses. Indication of position of the robot is important for his orientation in space. Mapping and localization of an image of an object is carried out with use of the scanning laser range finders. For measurement of distance use ultrasonic sonars, infrared sensors, laser sensors. Achievement of an object is carried out on the received coordinates. Procedures of realization of behavior are performed by the movements of parts of motor mechanisms of the robot according to a route of movement and the sequence of motive acts of parts of motor mechanisms of the robot. The route of the movement of the robot is under construction in classes of piecewise and polynominal functions.

Cybernetic methods realize functions, to touch human organs and allow creating robots with adaptive behavior on the basis of imitative thinking.

\section{Functional Structure of the Cognitive Professional Robot with Retraining}

The robot with symbolical language thinking has system of recognition of the interlocutor, system of speech input of information requirements, system of realization of information requirements (system of imitation of imitative thinking), network system of synthesis of the speech in the text of realization of information requirement [4-7].

The system of realization of information requirement contains system of assimilation of knowledge, system of symbolical and language communication, system of training, base of knowledge, abilities base, the neural network system of reading printing system and system of graphic display 
(Figure 1). The system of training contains subsystems of machine translation. The system of recognition of

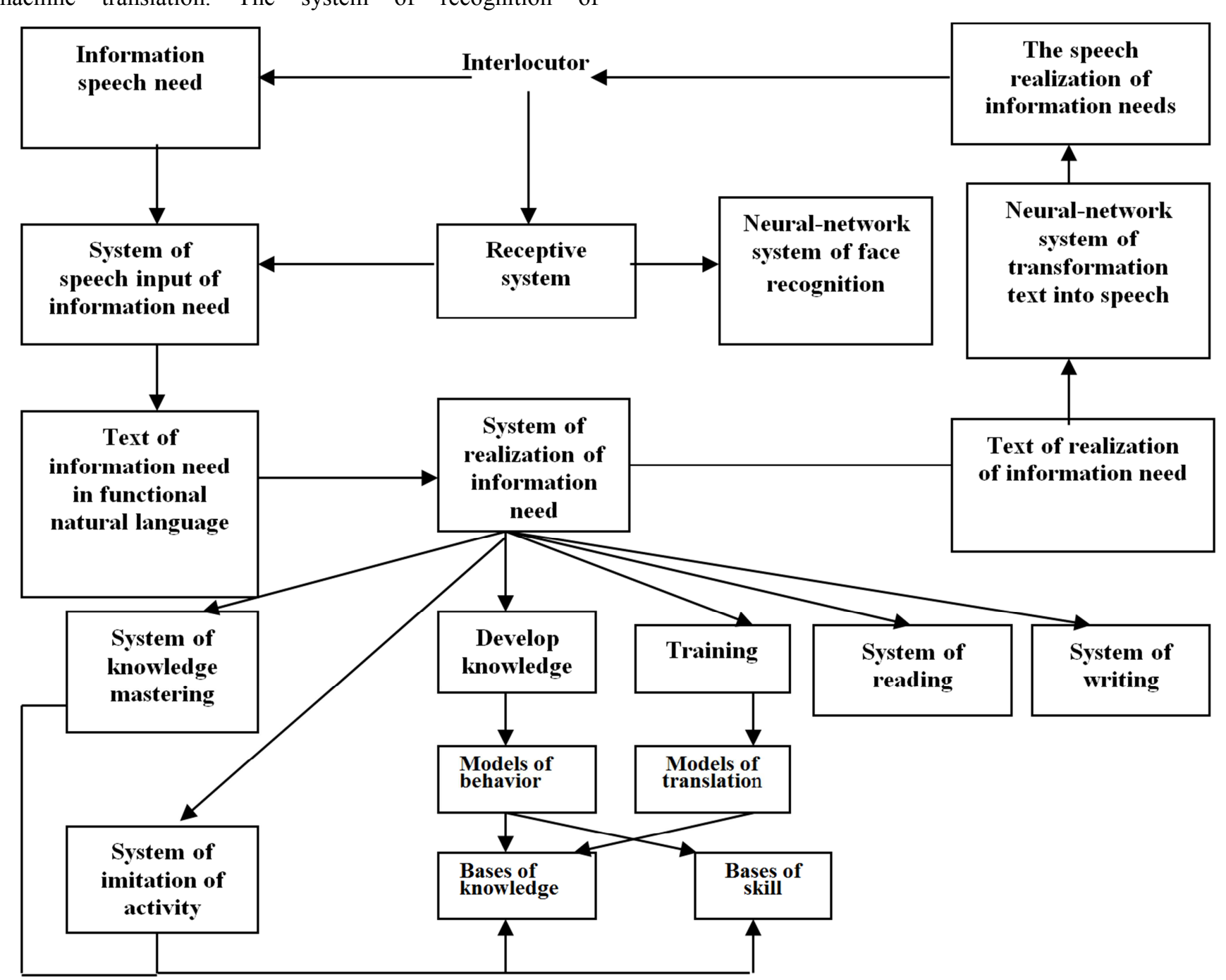

Figure 1. Functional structure of the robot.

Information unit of communication between the robot and the interlocutor is information requirement. The interlocutor uses information requirements which contain in the knowledge base of the robot. He communicates with the robot by means of combinations of information requirements, enriching, thereby, the robot with information requirements. The robot receives new basic information requirements, elements of knowledge and realization during his training.

Acquaintance of the robot to the person is carried out through neural network system of face recognition. If the person is unknown to the robot, then the receptive system remembers his speech dictionary and the person. If he is known to the robot, then the system will customize system of speech input of information requirement on the speech dictionary of the interlocutor. After that information contact between the robot and the person begins. The system of speech input will transform speech information requirement to the text in a functional natural language.

Specialization of cognitive adaptive robots is carried out on the basis of knowledge bases, bases of abilities and implementers of behavior. Cognitive adaptive robots with imitative thinking and adaptive behavior have prospect of broad practical application.

\section{Cognitive Methods Structuring, Classification Identification of Knowledge by Logical Formats}

\subsection{Cognitive Method of Search of Regularities}

Process of cognitive search of regularities consists of two stages: cognitive analysis of knowledge; identification of regularities by forecasting methods by results of the analysis.

The cognitive analysis of data uses mathematical methods and algorithms, the systems of data processing and technology of visual representation of data.

Cognitive methods of the analysis of data: statistical methods, methods of computer mathematics, optimizing methods, expert methods, synergetic methods, methods of 
indistinct sets, methods of fractal mathematics, methods of conflict situations.

Algorithmic systems of data processing: subject-oriented analytical systems, the systems of the statistical analysis, the trained neural networks, associations on analogies, trees of decisions, evolutionary programming, algorithms of search, the system of visualization of multidimensional data.

Methods of the forecast of situations: the determined forecast, the statistical forecast, a method of program forecasting, a method of heuristic forecasting, temporary ranks, extrapolation method, expert method, the forecast on the basis of linear regression, the interpreted method, the case analysis, the synergetic analysis, the evolutionary statistical forecast.

The tasks solved by cognitive methods of the analysis of data: detection and assessment of the hidden regularities, detection and assessment of influence of the hidden factors, assessment of the current situation, the forecast of development of the situation, formation and optimization of the operating decisions.

\subsection{Data Processing Languages}

Language of statistical researches $\mathrm{R}$ contains a wide range of various functions (temporary ranks, forecasting, classification, clustering) and allows carry out profound analytics: identification of the facts, entities or objects; to define subject; to carry out classification.

The Python language contains means of statistical modeling and processing of big data flows.

The MATLAB language contains means of processing of stream information, the analysis of the obtained and predicted data in the field of scientific research.

\subsection{Digital Systems of Modeling}

Deductor - the analytical platform developed by the Base Group Labs company. The most demanded analysis algorithms (trees of decisions, neural networks, the selforganized cards, etc.) are built in Deductor, there are tens of ways of visualization and integration into a set of sources/receivers of data is provided. In system technologies which on the basis of uniform architecture allow pass all stages of creation of the analytical platform are applied: from creation of storage of the models given before automatic selection and visualization of the received results.

SAS Enterprise Miner is the software product developed for the purpose of creation of exact predictive and descriptive models on the basis of large volumes of information.

The software of STATISTICA uses algorithms of access to data, their transformations and creation of predictive models.

\subsection{Cognitive Technology of Search of Regularities}

The machine technology at which the computer analyzes experimental data and writes own program of detection of statistical regularities is cognitive technology. The cognitive machine technology helps to take new regularities effectively.

Mathematicians of Deep Mind company have developed an algorithm of machine learning IMPALA which allows separate parts of system to study performance of several tasks at once, and then to exchange data among themselves. On the basis of similar algorithms, temporary ranks and the systems of modeling Deductor, SAS Enterprise Miner and STATISTICA it is possible to receive set of the regularities and data sufficient for creation of models of nanostructures with necessary parametrical and structural resonant properties.

\section{Robot with Technological Thinking and Behavior on Service of Society}

Psyche of the person since the birth in the course of language communication acquires entities in the form of sensual elements of knowledge. The intrinsic dictionary, defining semantic use of morphological words, is necessary for technological thinking of robot, which does not have psyche. Technological thinking of cognitive robots is implemented on the basis of communicative associative logic [6]. Engineers and programmers create cognitive methods of structuring and classification of Smart knowledge for identification of regularities by logical format [7].

Robots become independent subjects of social environment [8-21]. Social cognitive smart robots are used as guide, seller, lecturer, vacuum cleaner, nurse, volunteer, security guard, administrator of hotel. Smart guide (Figure 2).

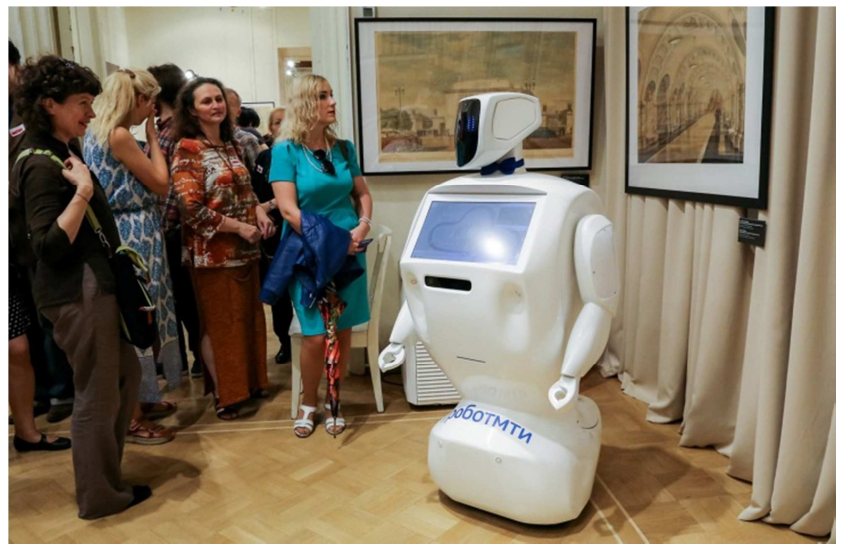

Figure 2. Russian robot guide.

Smart robot-seller of robotic café and drugstores (Figure $3)$. Consultant, lecturer and teacher (Figure 4). Nurse in hospitals (Figure 5). Smart robot vacuum cleaner (Figure 6). Robot-Android volunteer ASIMO (Figure 7). Mobile robot security guard Atlas (Figure 8). Chinese humanoid robot (Figure 9). Japanese robot-administrator of hotel Henn-na Hotel (Figure 10). 

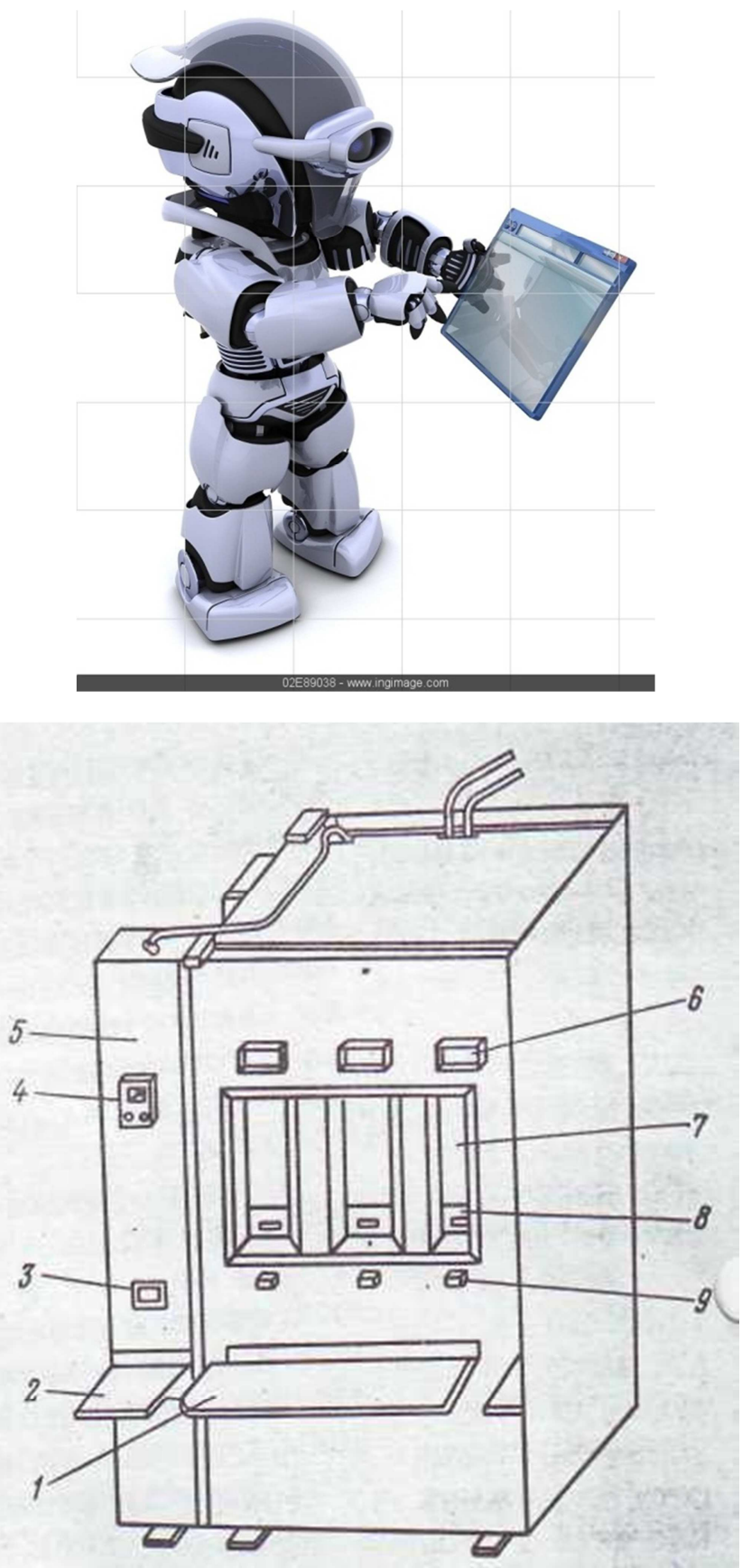

Figure 3. European cognitive professional robot-seller of café.

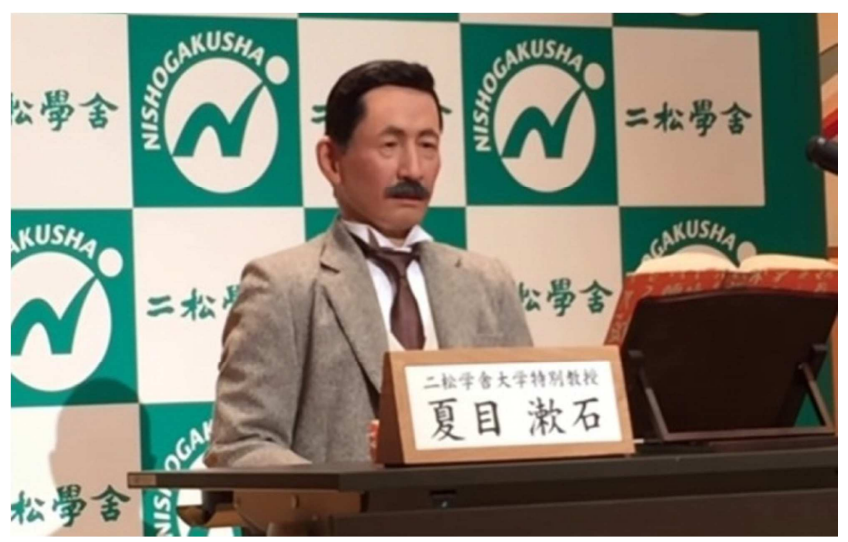

Figure 4. Japanese robot lecturer.

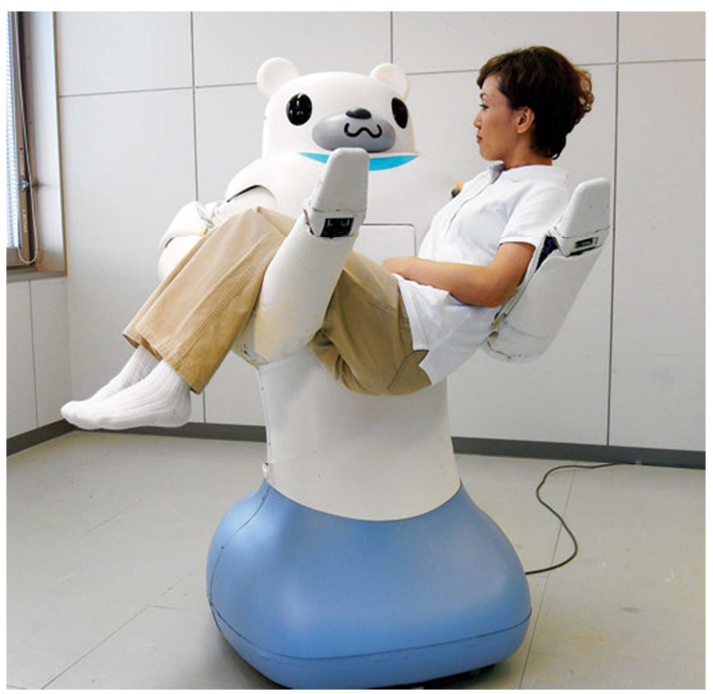

Figure 5. Japanese robot nurse.

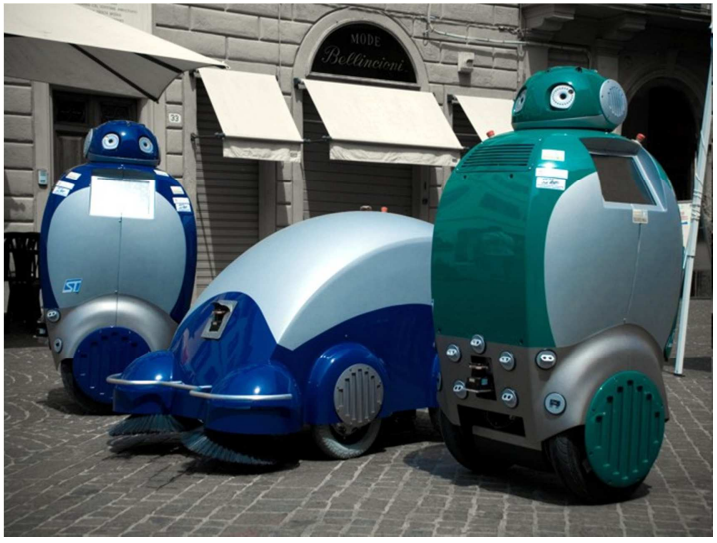

Figure 6. European smart robot vacuum cleaner.

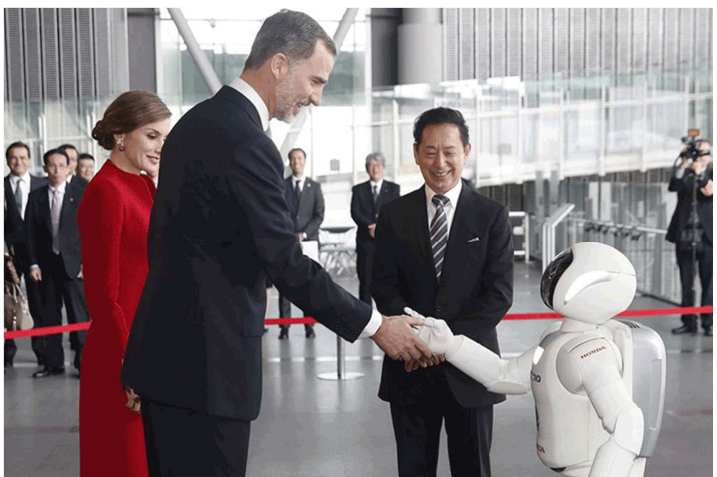

Figure 7. Japanese robot-Android volunteer ASIMO.

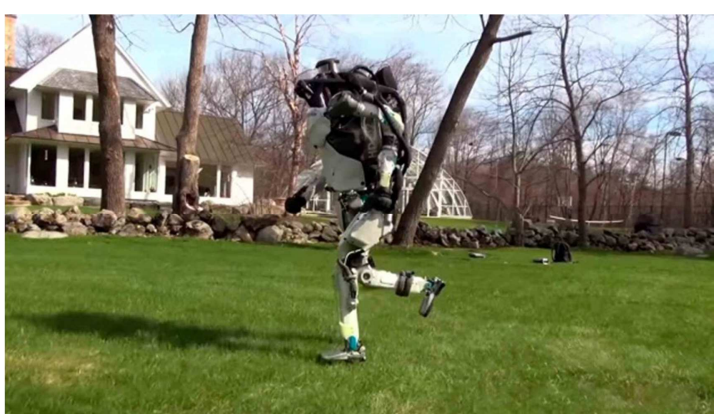

Figure 8. American mobile robot security guard Atlas. 


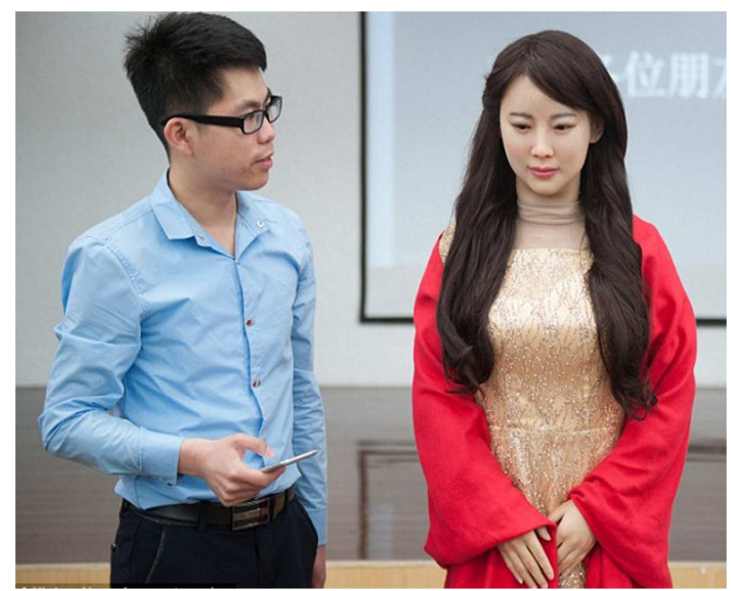

Figure 9. Chinese humanoid robot (Jia Jia).

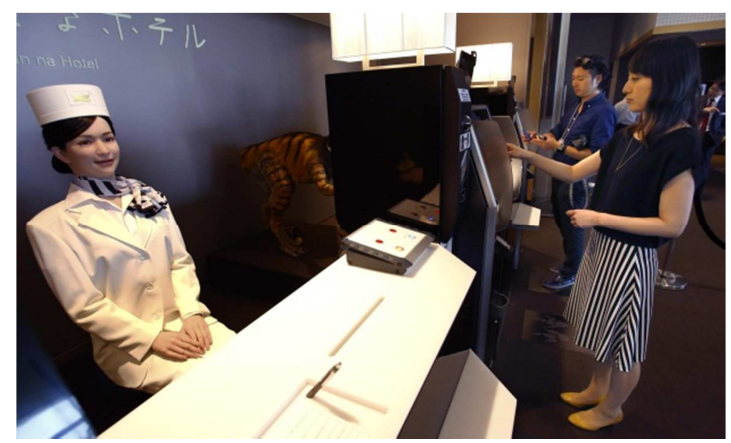

Figure 10. Japanese robot-administrator of hotel Henn-na Hotel.

\section{Robotic Smart Drugstores}

Cognitive professional robot is possible to train and use as sellers of smart drugstores [2-7]. Visitors of smart drugstores are served by cognitive professional robot (Figure 2) and the automatic machine of piece drugs. The robot has the neural network trained system of communication with visitors for booking, the device of reading of electronic money from the plastic card of the visitor and the device of distance steering by the program controller of the automatic machine for delivery of drugs. The automatic machine of delivery of products under control of the robot serves orders of visitors. The visitor inserts the plastic calculated card into the device of reading of electronic money, reports to the robot the list of drugs of the order. The robot through the system of booking and the program versatile controller of the automatic machine activates trays with drugs according to the order. When the order is created by automatic machine for delivery of drugs, the robot reads out electronic money from the plastic card of the visitor, at the prices of drugs. After the visitor receives a set of drugs of the order from the automatic machine, takes away the calculated plastic card and the check.

\section{Conclusion}

The cognitive robots with communicative and associative logic of thinking having the systems of machine retraining of realization of information requirements will be able quickly to change professional qualification and competences.
The international scientific and engineering society gradually moves to technical realization of the cognitive professional robot with retraining.

In the future in labor market cognitive robots with retraining will perform professional works, and the person will occupy a niche of scientific research of creative innovative activity.

\section{References}

[1] Evgeniy Bryndin Robot with imitative thinking. PNIPU bulletin: Electrical equipment, Information technologies, Control systems", N. 14. PNIPU. 2015. P. 5-36.

[2] Bryndin E. G. Cognitive robots. Inter. Conf. "Management of development of large-scale systems (MLSD'2016). M.: IPM RAS. Pages 285-294. 2016.

[3] Evgeniy Bryndin. Cognitive Robots with Imitative Thinking for Digital Libraries, Banks, Universities and Smart Factories. International Journal of Management and Fuzzy Systems. V. 3, N. 5, 2017, pp 57-66.

[4] Evgeniy Bryndin. Program Hierarchical Realization of Adaptation Behavior of the Cognitive Mobile Robot with Imitative Thinking. International Journal of Engineering Management. V. 1, Issue 4. 2017, pp. 74-79.

[5] Evgeniy Bryndin. Technological Thinking, Communication and Behavior of Androids. Communications. Vol. 6, No. 1, 2018. Pages: 13-19.

[6] Evgeniy Bryndin. Communicative Associative Logic of Cognitive Professional Robot with Imitative Thinking. Journal Engineering Mathematics, Volume 2, Issue 2. 2018. Pages: $79-85$.

[7] Evgeniy Bryndin. Directions of Development of Industry 4.0, Digital Technology and Social Economy. American Journal of Information Science and Technology. V 2, Issue 1. 2018. P. 917.

[8] Evgeniy Bryndin. Cognitive smart robots with technological thinking and behavior for industry and social sphere. /Science, Technology and Life: Proceedings of articles the V International scientific conference. - Czech Republic, Karlovy Vary. 2019. ISBN 978-80-7534-195-2.

[9] Evgeniy Bryndin. Digital technologies of the industry 4.0. / Chepter 10, C. 201-222, Book: Computer Science Advances: Research and Applications.. USA: Nova Science Publisher. 2019. 252 pages.

[10] Bollier, D. (2017). Artificial intelligence comes of age. The promise and challenge of integrating AI into cars, healthcare and journalism. Washington, DC: The Aspen Institute.

[11] Dunis, C. L., Middleton, P. W., Karathanasopolous, A., \& Theofilatos, K. A. (Eds.). (2017). Artificial Intelligence in Financial Markets: Cutting Edge Applications for Risk Management, Portfolio Optimization and Economics. London: Palgrave Macmillan.

[12] Ivanov, S., \& Webster, C. (2017). The robot as a consumer: a research agenda. Paper presented at the "Marketing: experience and perspectives" Conference, 29-30 June 2017, University of Economics-Varna, Bulgaria, pp. 71-79. 
[13] Frey, C. B., \& Osborne, M. A. (2017). The future of employment: how susceptible are jobs to computerisation? Technological Forecasting and Social Change, 114, 254-280.

[14] La Grandeur, K. and Hughes, J. J. (Eds.) (2017). Surviving the Machine Age. Intelligent Technology and the Transformation of Human Work. London: Palgrave Macmillan.

[15] Makridakis, S. (2017). The Forthcoming Artificial Intelligence (AI) Revolution: Its Impact on Society and Firms. Futures, 90, 46-60.

[16] West, D. M. (2018). The future of work: Robots, AI, and automation. Washington: Brookings Institution Press.

[17] Kiggins, R. (2018). The Political Economy of Robots: Prospects for Prosperity and Peace in the Automated 21st Century. Cham: Palgrave Macmillan.
[18] Ivanov, S., \& Webster, C. (2018). Adoption of robots, artificial intelligence and service automation by travel, tourism and hospitality companies - a cost-benefit analysis. In Marinov, V., Vodenska, M., Assenova, M. \& Dogramadjieva E. (Eds) Traditions and Innovations in Contemporary Tourism, Cambridge Scholars Publishing, pp. 190-203.

[19] Bhaumik, A. (2018). From AI to Robotics: Mobile, Social, and Sentient Robots. Boca Raton, FL: CRC Press.

[20] Daugherty, P. R., \& Wilson, H. J. (2018). Human + machine: Reimagining work in the age of AI. Boston, MA: Harvard Business Review Press.

[21] Carrozza, M. C. (2019). The Robot and Us: An 'Antidisciplinary' Perspective on the Scientific and Social Impacts of Robotics (Vol. 20). Cham: Springer. 